\title{
Several Problems in the Development of Social Work in China
}

\author{
Chuang Yan \\ Department of Marxism, Northeast Normal University, Changchun, Jilin, China
}

Keywords: Social Work; Development; Problems.

\begin{abstract}
The process of social change in China requires the coordination and support of social work. However limited to the current situation of "low starting point, weak base", China's current social work is facing multiple difficulties and challenges. This paper analyzes and answers several important problems encountered in the development of social work in China, tries to clarify the core content and key issues, and combs ideas for the healthy development of social work.
\end{abstract}

\section{Introduction}

Social work, as a "self-help" social activities, with the religious charity and government relief activities carried out, was eventually born in British society in the early 19th century. Later, with the deepening transformation from the industrial society to post-industrial society, all kinds of the civil rights movement and the new workers' movement occurred repeatedly, Europe and the United States were faced with a lot of new social problems and social conflicts. To this end, countries adopted a series of "social plan" and social welfare policies to adjust the pattern of interests, resolve social conflicts, maintain social stability, promote economic and social development. In this process, these countries gradually realized that the implementation of these "social programs" and welfare policies apparently couldn' t rely on a single, limited government resources and administrative power. It couldn' t only rely on non-governmental and non-profit social service agencies either. It needed to establish institutional arrangements for the effective integration of resources and the co-governance of governmental and non-governmental organizations. It was necessary to establish a set of policy guidance and legal norms that was conducive to the development of non-governmental organizations, as well as mechanisms for interaction between government and non-governmental organizations under the principle of social division of labor. In this context, the social work system with professionalization, specialization and socialization emerged. As the most important carrier of non-governmental organizations and non-profit organizations, social work agencies developed rapidly. Between government and social work institutions, there was a cooperative mechanism for the purchase of social services and the provision of social services.1

China, as a typical post-development country, is also faced with the historical task of promoting social welfare and maintaining social stability. Therefore, it is also necessary to develop social work to accelerate the realization of these tasks. But the social work in China as a discipline and professional fields has just started, it has become the universal pursuit and dream of contemporary Chinese social workers on how to learn from the mature experience of the development of social work in Europe and America and combine with the characteristics of contemporary Chinese society to build the same characteristics of China's social work. Therefore, in this paper, the author combines the experience and thinking of the Chinese society, and makes extensive analysis on several major problems in the development of Chinese social work. 


\section{Adhere to the Social Work Development Forms Focusing on Both Administrative Social Work and Professional Social Work}

In the academic sense, social work was born in British and American countries in the early 19th century. Nowadays, it has developed a specialized system of methods, including case work, group work and community work. It has accumulated a lot of theories and methods for dealing with social conflicts effectively, and has been widely introduced and promoted by all countries in the world. Although this professional social work is a foreign thing for our country, in terms of the need and methods for dealing with social contradictions, China also has a long history of "social work". It manifests as a special form of administrative social work. Such social work content is not from the professional social workers or social work institutions, but by the social work activities organized by the government, such as the Labor Union, the Communist Youth League, Women's Federations and Disabled Persons' Federation.

In the promotion of social development, the government on behalf of the public interest and the public on behalf of private interests is undoubtedly the two basic forces. However what kind of force plays a leading role in the development of social work has been a matter of constant debate among domestic scholars. Some scholars emphasize that the government plays the leading role in the development of social work. They believe that with the strong backing of the government, various measures of social work can be nationwide implemented, and ideal of the rapid development of social work can be achieved ultimately. The other scholars emphasize that the public plays the leading role in the development of social work. They believe that the history of social work is a demonstration of the power of the people. At the same time, they think that the government can' $t$ accurately predict the various needs in the development of domestic social work, but the public can find and supply new needs at any time during the process of promoting the development of social work. Thus, the administrative social work is the way of social work development driven by the government, and the professional social work is the way of social work development driven by the public.

Nowadays, China is experiencing a planned institutional transformation under the guidance of the government. The government's understanding and control of this transformation is completely different from the spontaneous social change process in Europe and America in history. Chinese government is fully capable of understanding and controlling the social work in this transformation. At the same time, China, as a typical post-development country with a strong central government, can quickly promote the construction of social work and avoid all kinds of mistakes made in Europe and America through the power of the government. Therefore, China's current social work should adhere to the development forms focusing on both administrative social work and professional social work.

\section{Adhere to the Working Methods Focusing on Both Administrative Social Work and Professional Social Work}

In the early days of social work, the work tasks were relatively complicated, and the various theories entered into the field of it. Knowledge of sociology, psychology and philosophy has become the dominant theory of social work. The theory of social structure function theory and other theories have also occupied the dominant position in this field, which has led to the prosperity in the development of social work. All kinds of intervention patterns and methods are popping up all the time. The situation began to change in the 1970s. Around the goal of increasing the degree of specialization of social work, all kinds of basic theory, knowledge, work methods and techniques are constantly integrated, eventually formed a mainstream intervention mode and working methods guided by the classical theory faction. Through this integration process, which aims to enhance the degree of specialization, social work transformed from "social business" into a professional discipline. It has the basic characteristic of a professional subject, that is, social work has a relatively strict set of theoretical knowledge and values. This is, of course, at the expense of some working methods and the theoretical knowledge. 
The integration process that takes place in the field of social work is with the need of discipline development and the inevitability of history. As is known to all, after the birth of social work, due to the complexity of participation subjects and the lack of its own system of theoretical knowledge, social work has been attributed to the field of clinical treatment technology. It did not get a relatively independent academic status. American social worker Mary Richmond wrote a book called Social Diagnosis for this. It opened the prelude of the discipline construction of social work. As a general rule for the development of the subject, the history of subject development will start from the open development and transfer to the integrated development. The same is true of social work which is a social science subject. However, in order to eliminate the needs of these disciplines, as a social job to resolve social contradictions and to deal with social problems, its working methods must be broad-based and comprehensive developed, in order to seek the effective implementation of the results. Therefore, the development of social work in China is bound to integrate local knowledge and culture, form a social work theory with Chinese characteristics, construct the professional theory and practice system of social work which adapts to the needs of Chinese society. The development should combine the western social work philosophy with the basic requirements of Chinese cultural tradition, living habits and society, and take the road of comprehensive development.

Nowadays, the development of social work spans the special stage of discipline specialization. The professional goal of discipline has become the secondary target of social work development. Effective solution to social problems and social contradictions jump to the important goal of social work development. As a "self-help" social activities, how to meet the comprehensive needs of individuals and achieve the purpose of helping people, naturally promote social work to a comprehensive direction. It is even possible to say that social work is open in the discipline of knowledge. It will absorb all relevant knowledge as part of its scientific system.2 Therefore, professional social work and integrated social work do not conflict with one another. Professional social work is based on integration, and integrated social work is guided by profession. It is predicted that social work will develop in accordance with a trend of focusing on both professional aspect and comprehensive aspect.

\section{Establish the Cultivating Ideas that Qualified Social Work Comes First}

Today, the economy is growing fast and new social problems are emerging. Social work, as a social activity which is "self-help" and promote social welfare, has more demands. However, it is difficult to solve the requirements of complex social problems in the traditional neighborhood social work model. Volunteers who are engaged in social work without professional training tend to make the issues worse, which will harm the image and social status of professional social work. The so-called "social work of all people" means that all members of society are both the promoter of social work and the beneficial owners. This is a manifestation of the demands of the socialist interpersonal relationship. Qualified social work mainly refers to the people who engage in social work must pass the relevant vocational qualification examinations with their corresponding professional knowledge, and treat social work as their own career. Only by gaining social recognition can social work attracts more social members to participate and engage in. Only by qualifying the certification can the service quality of social work satisfy the clients.

Developing qualified social work must establish and improve the educational and training system of social work. From the perspective of the professional orientation, social work is a theoretical and practice-oriented social service occupation and social science disciplines. It originates from the activities such as the practice of social problems and the implementation of social assistance. This is different from other humanities and social sciences. Therefore, it is important to pay attention to the following relations in the development of this discipline. Firstly, in the nature of the subject, it is necessary to deal with the relationship between academic education and professional education. We should strengthen social science, political science, economics and social analysis, while also focusing on professionalism and practice. Secondly, the relationship between micro level and macro level should be well dealt with in the course design. Social workers should not only pay attention to the whole social problems and but also pay attention to personal treatment so that the content of 
curriculum structure and social development can be the embodiment of each other. Thirdly, the issue of professionalism and universality should be dealt with in the aspect of content. The primary training should focus on generality, which will enable the training object to have a basic capability. High-level training requires more specialized training.3 Finally, through the establishment and perfection of education and training system of social work, the construction of social work is promoted and formed.

\section{Scientifically Deal with the Relationship between Social Work and Social Policy}

Social policy is the various principles or policies adopted by the state or government to solve social problems, improve social environment and promote social justice and social progress.4 From this explanation, we can clearly see that the government has strongly involved in the social policy. On the other hand, Social work as a "self-help" social activity, the social intervention color is heavier. How to handle the relationship between the two and divide the scope of their respective functions? It is a problem that must be clearly solved in contemporary Chinese society. After all, the development of social work in China is largely driven by the government. In other words, social work and social policy are inextricably linked. The traditional social work in China is characterized by administrative characteristics, therefore, in the process of social transformation, while responding and solving social problems, and enhancing social welfare, China's social work obviously still plays an assistant role. Professor Wang (Sibin Wang)calls it "the embedded development of social work". This situation not only limits the intensity and scope of social work involved in social problems, but also makes the members of the community lack the awareness of the importance of social work. Therefore, it is an important prerequisite for the professional and specialized development of social work to rationally locate the relationship between government intervention and social work and establish effective social work mechanism.

Along with the deepening of the economic marketization process in our country, the responsibility of "small government and big society" is gradually formed. The line between government and social work is becoming clearer. Professional social work will be more and more important in solving social problems and social services. In the process of social transformation in the present, social workers should be objective to understand the connection degree between social work and social policy. They should actively manage relations with relevant government departments and mass organizations. They should establish a harmonious relationship with the departments and people that are likely to be helpful in social work, and participate in the activities of solving social problems together. They should also train social workers and social volunteers to achieve mutual understanding and integration between the two sides. At the same time, since the government controls almost all the social resources, it is necessary to reasonably ravel the relationship between government intervention and social intervention for the professional and specialized development of social work in China.2 Thus, We should think on the subject of intervention. Global issues should be firmly rooted in government intervention, regional issues can be resolved by social intervention. With the deepening of social change and social transformation in China, the interests of all sectors will continue to divide and adjust, and social problems and various contradictions will also show an upward trend. It will not only enrich the content of related fields of social science, but also have a very important theoretical and practical significance for the sustainable development of contemporary Chinese social transformation and the construction of a socialist harmonious society by developing social work with Chinese characteristics. Therefore, we must establish confidence and keep making progress. It is necessary to rationally deal with the "low starting point" of social work and the objective situation of the weak base. Don't be afraid of difficulties and have the courage to bring forth new ideas. We should also make efforts to promote the construction of social work in China on the basis of drawing lessons from the mature experience of Europe and America. 


\section{References}

[1] Yongxiang Xu. On the Construction Function of Modern Social Work in Harmonious Society, Journal of Xuehai, 2005(1)

[2] Sibin Wang (chief editor). Introduction to Social Work, Peking University Press, 1998, p12.

[3] Suju Lu. The Status Quo and Countermeasures of Professionalization and Specialization of Social Workers, Research on Educational Development, 2005(10)

[4] Yingsheng Li(chief editor). Introduction to Social Work, Renmin University of China Press, 2004, p214. 